\title{
A comparative study of surgical accesses to breast fibroadenoma
}

\author{
Chandan A. ${ }^{1}$, Ali I. ${ }^{2}$, Manerikar K. ${ }^{3}$, Singh G. ${ }^{4}$ \\ ${ }^{1}$ Dr. Amit Chandan, Junior Resident, ${ }^{2}$ Dr. Iqbal Ali, Professor \& Head of Unit, ${ }^{3}$ Dr. Kshitij Manerikar, Senior Resident, all \\ authors are affiliated with Department of Surgery, Dr D. Y. Patil Medical College, Hospital \& Research Centre, Pimpri, Pune, \\ affiliated with Dr D. Y. Patil Vidyapeeth, Pune, Maharashtra, India, ${ }^{4}$ Dr. Gurjit Singh, Professor of Surgery, Mahsa \\ University, Kuala Lampur, Malasia.
}

Corresponding Author: Dr. Iqbal Ali, Professor, Department of Surgery, Dr D Y Patil Medical College, Pune, Maharashtra, India, Email: chandan.amit@gmail.com

\begin{abstract}
Introduction: A Breast lump is a major health concern amongst women.Increased awareness has resulted in patients seeking early surgical consultation. Surgical resection is traditionally done by Fibroadenoma excision through an overlying incision (FETOI). This technique results in marked scarring. Another approach to Fibroadenoma excision through a periareolar incision (FETPI), which pays special attention to incision location to preserve cosmesis. In this study we assessed the cosmetic superiority and early complications of employing these two incisions in patients with fibroadenoma. Materials and Methods: A prospective non-randomised study of 70 patients who were divided into two groups as per the criteria described in materials and methods section, was carried out in our hospital between April 2015 to September 2017. Examination carried out in detail and diagnosis was established by clinical examination and USG of breasts followed by FNAC of lump. Patients were subjected to FETPI and FETOI Procedures and results were compared. Results: The incidence of early complications such as pain, hematoma and skin flap bruising at post-op day 1, day 2 and day 3 follow-ups did not differ significantly between two groups (P-value $>0.05$ for all). The distribution of total cosmetic score is significantly better in Group A compared than Group B (P-value $<0.001$ for all). The distribution of self-assessment score at post-op 1-month, 3-months and 6-months follow-ups is significantly better in Group A compared to Group B. Conclusion: The FETPI technique yields superior cosmetic and self-assessment results with minor incidence of early postoperative complications.
\end{abstract}

Key words: Fibroadenoma, Nipple, Risk factors, Biopsy, Pain, Sutures

\section{Introduction}

A Breast lump is a major health concern amongst women at any age as it invokes fear of malignancy. Increased awareness has resulted in patients seeking early surgical consultation. Early confirmation of diagnosis and treatment is necessary as the patient is under tremendous psychological stress.

Triple assessment of lump by clinical examination, ultrasonography (USG) and fine-needle aspiration cytology (FNAC) is a very useful diagnostic tool to evaluate breast lumps[1]. Among different benign breast conditions, Fibroadenomas (FAs) are the most common benign tumours occurring in women younger than 35 years. Conservative therapy has been tried for FAs, but it requires long term periodic monitoring ultimately causing anxiety and discomfort. Hence, only surgical resection is curative.

Manuscript Received: $28^{\text {th }}$ November 2017

Reviewed: $6^{\text {th }}$ December 2017

Author Corrected: $14^{\text {th }}$ December 2017

Accepted for Publication: $19^{\text {th }}$ December 2017
Two newer approaches, percutaneous excision and in situ cryoablation, have been developed and are less invasive than surgical excision [1]. However, these modalities are costly and not easily available. Surgical resection is traditionally done by Fibroadenoma excision through an overlying incision (FETOI). This technique results in marked scarring, which is a cause of concern in such patients. Another approach to Fibroadenoma excision through a periareolar incision (FETPI) has gained popularity, which pays special attention to incision location to preserve cosmesis as the scar is camouflaged in the dark areolar skin. FETPI is not possible if the lesion is far away from the areolar border or if the areola is small and the lesion is not underneath the areola.

Surgical removal is curative, and the most obvious approach to surgical excision is through an incision overlying the mass. That is why breast FA has been traditionally managed by FETOI, which often results in 


\section{Original Research Article}

marked scarring. Patients feel uncomfortable about the unsightly scar. The FETPI technique offers the advantage of an incision in an aesthetically acceptable area [1]. The periareolar scar is aesthetically superior to the overlying scar. In addition, if a lesion is $2-5 \mathrm{~cm}$ away from the areolar border, a subcutaneous tunnel, which may cause skin injury, is necessary to expose the lesion in the FETPI technique. Therefore, FETPI should be selectively and carefully performed.

Few publications have dealt in detail with the technical considerations necessary for successful execution of the
FETPI procedure. In our search of literature very few data was available that compared the benefits of using FETPI versus FETOI.

Need for the Study- This study was undertaken due to paucity of data available on comparisonof Fibroadenoma excision through a periareolar incision (FETPI) with Fibroadenoma excision through an overlying incision (FETOI). We also accessed the cosmetic superiority and early complications of employing these two incisions among patients.

\section{Materials and Methods}

Place of Study: Dr. D. Y. Patil Medical College, Hospital \& Research Centre, Pimpri, Pune 411018

Type of Study: A Prospective Study

Period of Study: April 2015 to September 2017

Period required for Data collection: 2 years

Period required for Data analysis and reporting: 6 months

\section{Inclusion Criteria}

\section{GROUP A:}

- Patients with areolar diameter greater than $3.5 \mathrm{~cm}$.

- Maximum distance from outer margin of mass to the nearest areola edge equal or less than $5 \mathrm{~cm}$.

- Fibroadenoma size $<3 \mathrm{~cm}$.

- Age equal or less than 35 years.

- Multiple and bilateral FA cases.

\section{GROUP B:}

- Patients with areolar diameter less than $3.5 \mathrm{~cm}$.

- Distance from outer margin of mass to the nearest areola edge more than $5 \mathrm{~cm}$.

- Fibroadenoma size $>3 \mathrm{~cm}$.

- Age equal or less than 35 years.

- Multiple and bilateral FA cases.

\section{Exclusion Criteria for Both the Groups:}

- Recurrent Fibroadenoma.

- Suspicion of Malignancy.

- Non-Palpable Lesions.

Sample Collection: Detailed clinical history and examination findings were recorded. Both groups of patients were subjected to routine blood examination, Chest X-ray and ECG, USG Breast (Both), FNAC of Breast Lump and Histopathological examination (HPE) of excised specimen post-operatively.

Group A patients underwent FETPI procedure as follows: The incision was marked preoperatively, with the patient in a supine position and arms abducted 90 degrees on arm boards. Aperiareolar skin incision was made on the marking at the areolar border. Excision of the tumor with approximately $0.5 \mathrm{~cm}$ rim of normal tissue was done. The skin was approximated using a running subcuticular stitch with 4-0 absorbable sutures.

Group B patients underwent FETOI procedure as follows: A curved/radial incision was made over the lump. The rest of 
the dissection was same as for the FETPI group.

Excised specimen wassent for histopathological confirmation of diagnosis and classification into Simple and Complex types. Early postoperative complications were assessed during first three post-operative days (D1, D2 and D3). Pain -was assessed using Visual Analogue Scale. Hematoma-Present (p)/Absent (a). Skin bruising- Present (p)/ Absent (a). Follow-up was done at intervals of 1,3 and 6 months after surgery and following parameters were assessed: -

1) Scar was assessed using Stony Brook Scar Evaluation Scale (SBSES) [2]:

\begin{tabular}{|c|c|c|}
\hline \multirow{2}{*}{ Width } & $\begin{array}{c}>2 \mathrm{~mm} \\
\leq 2 \mathrm{~mm}\end{array}$ & 0 \\
& Elevated/depressed in relation to surrounding skin Flat & 0 \\
\multirow{2}{*}{ Height } & Darker than surrounding skin & 1 \\
\hline \multirow{2}{*}{ Colour } & Same color or lighter than surrounding skin & 0 \\
& Present & 1 \\
\hline \multirow{2}{*}{ Suture marks } & Absent & 0 \\
\hline \multirow{2}{*}{ Overall appearance } & Poor & 0 \\
& Good & 1 \\
\hline
\end{tabular}

A total cosmetic score was calculated by adding the individual scores on each of the five categories ranging from 0 (worst) to 5 (best).

2) Self-assessment: Patient feelings regarding cosmetic outcome was rated by asking them to assess the scar on a scale of 1 to $4(1=$ excellent; $2=$ good; $3=$ fair; and $4=$ poor $)$ at 1,3 and 6 months interval after surgery.

3) Nipple sensation: Loss of sensation was recorded using cotton wick for touch, Pressure specified sensory device for pressure \& pinprick test for pain at 1,3 and 6 months interval. Nipple sensation was rated as 1 (good) or 2 (sensation loss).

Stastical Method - Descriptive statistics measures such as n (\%) and mean \pm standard deviations (SD) were used to present the data on categorical variables and continuous variables respectively. The inter-group comparison of categorical variables were done using Chi-square test Or Fisher's exact probability test for 2 × 2 contingency table. The statistical significance of inter-group difference of means of continuous variables was tested using independent sample $t$ test or unpaired $t$ test.P-values less than 0.05 were considered to be statistically significant. The entire data is statistically analyzed using Statistical Package for Social Sciences (SPSS).

\section{Results}

The mean \pm SD of age of the patients studied in group A and group B was $27.34 \pm 4.58$ years and $26.17 \pm 3.67$ years respectively.

In our study of 35 patients in group A, none had areolar diameter less than $3.5 \mathrm{~cm}$ and all cases had areolar diameter more than $3.5 \mathrm{~cm}$ where as, all patients in group B, had areolar diameter less than $3.5 \mathrm{~cm}$. The distribution of areolar diameter did not differ significantly between two intervention groups (P-value $>0.05)$.

In group A, all patients (100.0\%) had maximum distance from outer margin of mass to the nearest areola edge less than $5.0 \mathrm{~cm}$ and none had it more than $5.0 \mathrm{~cm}$. In group B, all patients $(100.0 \%)$ had maximum distance from outer margin of mass to the nearest areola edge more than $5.0 \mathrm{~cm}$.

Table-1: comparison of post-operative pain s(vas) at day 1, day 2 and day 3 in patients in two groups:

\begin{tabular}{|c|c|c|c|c|c|c|}
\hline \multirow{2}{*}{ Pain Score } & \multicolumn{2}{|c|}{ Group A (FETPI) (n=35) } & \multicolumn{2}{|c|}{$\begin{array}{c}\text { Group B (FETOI) } \\
(\mathbf{n = 3 5})\end{array}$} & \multirow{2}{*}{ T-value } & \multirow{2}{*}{ P-value } \\
\cline { 2 - 5 } & Mean & SD & Mean & SD & & \\
\hline Day 1 & 3.71 & 1.51 & 3.74 & 1.50 & -0.079 & 0.937 \\
\hline Day 2 & 2.71 & 1.18 & 2.71 & 1.27 & 0.000 & 0.999 \\
\hline Day 3 & 1.37 & 1.00 & 1.23 & 0.73 & 0.681 & 0.498 \\
\hline
\end{tabular}




\section{Original Research Article}

The mean \pm SD of pain score of patients studied in group A at post-op day 1, day 2, day 3 follow-up was $3.71 \pm 1.51,2.71 \pm$ 1.18 and $1.37 \pm 1.00$ respectively. The minimum - maximum pain score at day 1 , day 2 and day 3 was $2-8,1-6$ and $0-4$ respectively. The mean $\pm \mathrm{SD}$ of pain score of cases studied in group B at post-op day 1, day 2, day 3 follow-up was $3.74 \pm$ $1.50,2.71 \pm 1.27$ and $1.23 \pm 0.73$ respectively. The minimum - maximum pain score at day 1 , day 2 and day 3 was $2-8,1-$ 6 and $0-3$ respectively.

The distribution of mean pain score at post-op day 1, day 2 and day 3 follow-ups did not differ significantly between two intervention groups (P-value $>0.05$ for all).[Table 1]

Table- 2: comparison of incidence of post-operative hematoma at day 1, day 2 and day 3 in both groups:

\begin{tabular}{|c|c|c|c|c|c|c|c|}
\hline \multicolumn{2}{|c|}{ Hematoma } & \multicolumn{2}{|c|}{ Group A (FETPI) $(n=35)$} & \multicolumn{2}{|c|}{$\begin{array}{c}\text { Group B (FETOI) } \\
(\mathrm{n}=35)\end{array}$} & \multirow{2}{*}{$\begin{array}{c}\text { Chi-Square } \\
\text { value }\end{array}$} & \multirow[t]{2}{*}{ P-value } \\
\hline & & $\mathbf{n}$ & $\%$ & 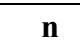 & $\%$ & & \\
\hline \multirow{2}{*}{ Day 1} & Absent & 30 & 85.7 & 29 & 82.9 & \multirow{2}{*}{0.108} & \multirow{2}{*}{0.743} \\
\hline & Present & 5 & 14.3 & 6 & 17.1 & & \\
\hline \multirow{2}{*}{ Day 2} & Absent & 30 & 85.7 & 30 & 85.7 & \multirow{2}{*}{0.000} & \multirow{2}{*}{0.999} \\
\hline & Present & 5 & 14.3 & 5 & 14.3 & & \\
\hline \multirow{2}{*}{ Day 3} & Absent & 32 & 91.4 & 31 & 88.6 & \multirow{2}{*}{0.159} & \multirow{2}{*}{0.999} \\
\hline & Present & 3 & 8.6 & 4 & 11.4 & & \\
\hline
\end{tabular}

In Group A, 5 patients (14.3\%) had hematoma on day 1, 5 cases (14.3\%) had it on day 2 and 3 patients (8.6\%) had it on day 3. In group B,6 patients (17.1\%) had hematoma on day 1,5 cases $(14.3 \%)$ had it on day 2 and 4 cases $(11.4 \%)$ had it on day 3.

The distribution of incidence of post-op hematoma at post-op day 1, day 2 and day 3 follow-ups did not differ significantly between two intervention groups (P-value $>0.05$ for all).[Table 2]

Table-3: comparison of incidence of post-op skin bruising at day 1, day 2 and day 3 in both groups

\begin{tabular}{|c|c|c|c|c|c|c|c|}
\hline \multicolumn{2}{|c|}{ Skin Bruising } & \multicolumn{2}{|c|}{ Group A (FETPI) $(n=35)$} & \multicolumn{2}{|c|}{$\begin{array}{c}\text { Group B (FETOI) } \\
(\mathbf{n}=\mathbf{3 5})\end{array}$} & \multirow{2}{*}{$\begin{array}{c}\text { Chi- } \\
\text { Square } \\
\text { value }\end{array}$} & \multirow[t]{2}{*}{ P-value } \\
\hline & & $\mathbf{n}$ & $\%$ & $\mathbf{n}$ & $\%$ & & \\
\hline \multirow{2}{*}{ Day 1} & Absent & 30 & 85.7 & 29 & 82.9 & \multirow{2}{*}{0.108} & \multirow{2}{*}{0.743} \\
\hline & Present & 5 & 14.3 & 6 & 17.1 & & \\
\hline \multirow{2}{*}{ Day 2} & Absent & 32 & 91.4 & 30 & 85.7 & \multirow{2}{*}{0.565} & \multirow{2}{*}{0.710} \\
\hline & Present & 3 & 8.6 & 5 & 14.3 & & \\
\hline \multirow{2}{*}{ Day 3} & Absent & 35 & 100.0 & 33 & 94.3 & \multirow{2}{*}{2.059} & \multirow{2}{*}{0.493} \\
\hline & Present & 0 & 0.0 & 2 & 5.7 & & \\
\hline
\end{tabular}

In group A, 5 patients (14.3\%) had skin bruising on day 1, 3 cases $(8.6 \%)$ had it on day 2 and none had it on day 3 . In group B, 6 patients $(17.1 \%)$ had skin bruising on day 1, 5 cases $(14.3 \%)$ had it on day 2 and 2 cases $(5.7 \%)$ had it on day 3 . The distribution of incidence of post-op skin bruising at post-op day 1, day 2 and day 3 follow-ups did not differ significantly between two intervention groups (P-value $>0.05$ for all). [Table 3]

Table 4: Comparison of post-operative cosmetic score at 1 month, 3 months and 6 months in both groups

\begin{tabular}{|c|c|c|c|c|c|c|}
\hline \multirow{2}{*}{$\begin{array}{c}\text { Total Cosmetic } \\
\text { Score }\end{array}$} & \multicolumn{2}{|c|}{ Group A (FETPI) $(\mathbf{n = 3 5})$} & \multicolumn{2}{|c|}{$\begin{array}{c}\text { Group B (FETOI) } \\
(\mathbf{n = 3 5})\end{array}$} & \multirow{2}{*}{ T-value } & \multirow{2}{*}{ P-value } \\
\cline { 2 - 6 } & Mean & SD & Mean & SD & & \\
\hline 1-Month & 2.97 & 0.82 & 1.51 & 0.89 & 7.129 & 0.001 \\
\hline 3-Months & 3.83 & 0.75 & 2.06 & 0.68 & 10.350 & 0.001 \\
\hline 6-Months & 4.34 & 0.64 & 2.57 & 0.61 & 11.880 & 0.001 \\
\hline
\end{tabular}

The mean \pm SD of total cosmetic score at 1-month post-op follow-up in Group A and Group B was $2.97 \pm 0.82$ and $1.51 \pm$ 0.89 respectively. The mean total cosmetic score at 1-month post-op follow-up is significantly higher in Group A compared 


\section{Original Research Article}

to Group B (P-value $<0.001)$. The mean $\pm \mathrm{SD}$ of total cosmetic score at 3-months post-op follow-up in Group A and Group B was $3.83 \pm 0.75$ and $2.06 \pm 0.68$ respectively. The mean total cosmetic score at 3-month post-op follow-up is significantly higher in Group A compared to Group B (P-value $<0.001$ ). The mean \pm SD of total cosmetic score at 6-month post-op followup in Group A and Group B was $4.34 \pm 0.64$ and $2.57 \pm 0.61$ respectively.

The mean total cosmetic score at 6-month post-op follow-up is significantly higher in Group A compared to Group B (Pvalue $<0.001)$ [Table 4].

In group A, majority of patients i.e. 18 (51.4\%) had Grade 3 cosmetic score at 1-month, 18 cases (51.4\%) had grade 4 at 3months and 17 (48.6\%) had grade 4 at 6-months post-op follow-up. Group B, majority of patients i.e. 15 cases (42.9\%) had grade 2 cosmetic score at 1-month, $22(62.9 \%)$ had grade 2 it at 3 -months and 17 cases $(48.6 \%)$ had grade 2 at 6 -months postop follow-up.

The distribution of grading of total cosmetic score at post-op 1-month, 3-months and 6-months follow-ups is significantly better in Group A compared to Group B (P-value $<0.001$ for all).

Table-5: Comparison of post-operative self-assessment score at 1 month, 3 months and 6 months in both groups:

\begin{tabular}{|c|c|c|c|c|c|c|c|}
\hline \multicolumn{2}{|c|}{ SelfAssessment Score } & \multicolumn{2}{|c|}{ Group A (FETPI) $(n=35)$} & \multicolumn{2}{|c|}{$\begin{array}{c}\text { Group B (FETOI) } \\
(\mathbf{n}=35)\end{array}$} & \multirow{2}{*}{$\begin{array}{c}\text { Chi-Square } \\
\text { value }\end{array}$} & \multirow[t]{2}{*}{ P-value } \\
\hline & & $\mathbf{n}$ & $\%$ & $\mathbf{n}$ & $\%$ & & \\
\hline \multirow{4}{*}{ 1-Month } & Excellent & 7 & 20.0 & 0 & 0.0 & \multirow{4}{*}{23.707} & \multirow{4}{*}{0.001} \\
\hline & Good & 16 & 45.7 & 8 & 22.9 & & \\
\hline & Fair & 12 & 34.3 & 13 & 37.1 & & \\
\hline & Poor & 0 & 0.0 & 14 & 40.0 & & \\
\hline \multirow{4}{*}{ 3-Months } & Excellent & 15 & 42.9 & 0 & 0.0 & \multirow{4}{*}{35.714} & 0.001 \\
\hline & Good & 20 & 57.1 & 15 & 42.9 & & \\
\hline & Fair & 0 & 0.0 & 19 & 54.3 & & \\
\hline & Poor & 0 & 0.0 & 1 & 2.9 & & \\
\hline \multirow{4}{*}{ 6-Months } & Excellent & 24 & 68.6 & 6 & 17.1 & \multirow{4}{*}{24.726} & \multirow{4}{*}{0.001} \\
\hline & Good & 11 & 31.4 & 16 & 45.7 & & \\
\hline & Fair & 0 & 0.0 & 13 & 37.1 & & \\
\hline & Poor & 0 & 0.0 & 0 & 0.0 & & \\
\hline
\end{tabular}

In group A, 23 patients (65.7\%) had excellent/good self-assessment at 1-month, 35 (100.0\%) had it at 3-months and 35 cases $(100.0 \%)$ had it at 6-months post-op follow-up. In group B, 8 patients $(22.9 \%)$ had excellent/good self assessment at 1month, 15 cases $(42.9 \%)$ had it at 3-months and $22(62.8 \%)$ had it at 6-months post-op follow-up. The distribution of self assessment score at post-op 1-month, 3-months and 6-months follow-ups is significantly better in Group A compared to Group B (P-value $<0.001$ for all)[Table 5].

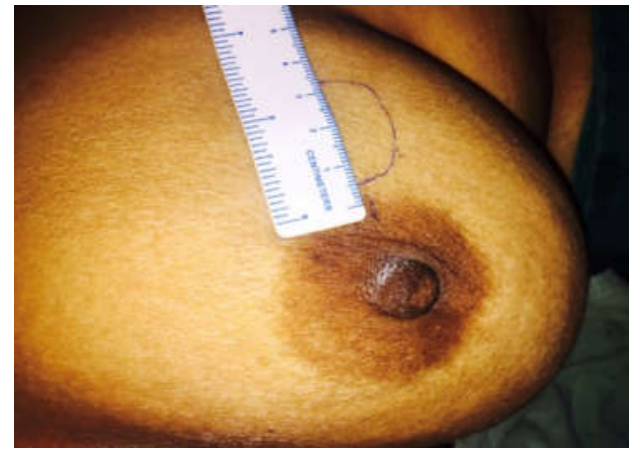

Image-1: Distance between areola and outer edge of lump.

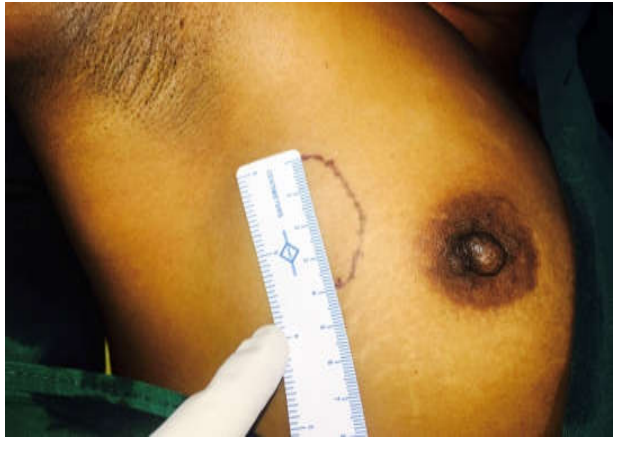

Image-2: Size of lump. 

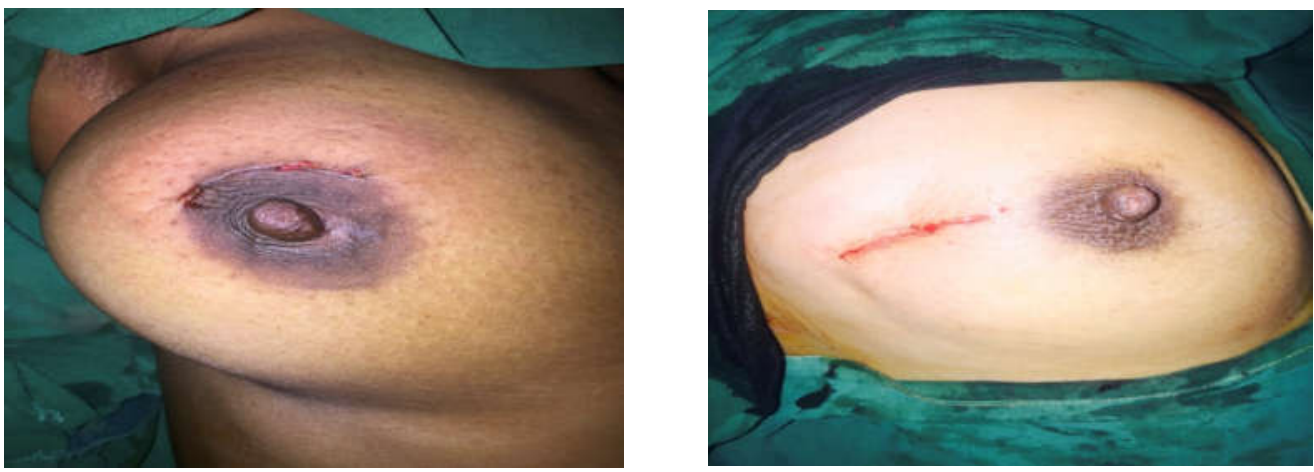

Image-3: Post-operative- fetpi (group a) incision. Image-4:Post-operative- fetoi (group b) incision.

\section{Discussion}

Benign breast disease is an important risk factor for a later breast cancer, which can develop in either breast[3]. The major determinants of the risk of breast cancer after the diagnosis of benign breast disease are histological features, the age at biopsy, and the family history of malignancy of breast.

Fibroadenomas are common benign breast lumps, which are solid tumors composed ofstromal and epithelial elements[1]. These are the second most common breast pathology, following fibrocystic disease, and occur in women younger than 35 years old, with the peak age of incidence in the third decade.FAs are a major cause of concern, particularly among younger females. Studies have shown that the surgical excision is the most suitable solution in those cases requiring treatment[4].

Fibroadenoma excision through a periareolar incision (FETPI) provides a better alternative cosmetically. FETPI was introduced first by Dufourmentel in 1928[5]. The incision was widely used in gynecomastia and in breast augmentation for a long time because of its cosmetic advantage. Cosmetic results were satisfactory in patients with palpable breast. FAs who had undergone operation through a circumareolar incision.

There are two pathological variants of FA namely Intracanalicular and Pericanalicular.Fibroadenomas can be classified as simple or complex according to histological features. Complex fibroadenomas differ from simple fibroadenomas because of the presence of cysts (>3 mm), sclerosing adenosis, epithelial calcifications, or papillary apocrine changes. Atleast $0.5 \mathrm{~cm}$. rim of tissue had to be present around the fibroadenoma to evaluate changes in the surrounding breast parenchyma.

Most FAs are clinically identifiable, whereas in $25 \%$ of cases, these are non-palpable and are diagnosed with mammography and ultrasound. Fine-needle aspiration/needle core biopsy can be useful in such cases. The advantage of needle core biopsy over fine-needle aspiration may be that it more easily reveals complex changes and epithelial proliferations. It is mandatory to know the preoperative cytology of the mass.

The majority of early complications post FA excision occurred in the early stage (within three days) due to tissue handling and flap dissection[3]. According to the one study, most of the complications were minor and preventable and they did not interfere with the esthetic outcome[5].

A total cosmetic score was calculated by adding the individual scores on each of the five assessment criteria such as width, height, colour, suture marks and overall appearance of the surgical site and the score ranges between 0 (worst) to 5 (best).

The periareolar technique does involve extensive dissection around the lactiferous ducts. Lactational problems could not be assessed in the context of the present study. However, to minimize damage to the lactiferous ducts, the dissection plane between subcutaneous fat and breast tissue should be identified and followed by pulling the edges of the incision upward.

In a study conducted by Liu et al, 76 patients who underwent FETPI and 82 patients who underwent FETOI (Group B) were retrospectively analyzed and he noted that, FETPI technique was associated with more early postoperative complications (7/76 vs. 2/82) and more nipple sensation losses (15/76 vs. $7 / 82)$ than those who underwent FETOI[6].

We observed that the incidence of pain at post-op day 1 , day 2 and day 3 follow-ups did not differ significantly between two intervention groups who underwent FETPI and FETOI in our study. 


\section{Original Research Article}

One study found that, Cosmetic assessment at 6 months demonstrated statistically more excellent/ good results in the technique FETPI than FETOI[5]. Another study comparing 36 patients undergoing FETPI with 40 patients undergoing FETOI concluded that the peri-areolar incision gave better cosmetic outcome at the cost of minor postoperative complications compared to the overlying incision technique[7]. In our study, we found that the mean total cosmetic score was significantly better in patients who underwent FETPI compared to patients who underwent FETOI.

Patient perspective regarding cosmetic outcome was rated by asking them to assess the scar on a scale of 1 to 4 ( $1=$ excellent; $2=$ good; $3=$ fair; and $4=$ poor) at 1,3 and 6 months interval after the surgery. Nipple sensation may decrease due to transaction of sensory nerves during the procedure[4].

Nipple sensation was assessed using cotton wick for touch, Pressure specified sensory device for pressure \& Pinprick test for pain at 1,3 and 6 months interval. Our results showed that significantly higher proportion of patients who underwent FETPI had better self assessment than those who underwent FETOI. These results were once again in agreement with few other studies[6,7].

Contribution of authors during study process: Amit Chandan helped in data collection \& was the first assistant in all operations of FA excision. KshitijManerikar handled the statistical analysis. Iqbal Ali was chief surgeon in all the cases \& Gurjit Singh did over all supervision.

\section{Conclusions}

We observed in our study that, the incidence of complications such as pain, hematoma and skin flap bruising at post-op day 1, day 2 and day 3 follow-ups did not differ significantly between two intervention groups who underwent FETPI and FETOI.

The mean total cosmetic score was significantly better in patients who underwent FETPI compared to patients who under went FETOI. Self assessment score at post-op 1month, 3-months and 6-months follow-ups was significantly better in Group A compared to Group B. We conclude, that FETPI technique yields superior cosmetic and self assessment results with minor incidence of postoperative complications and better than FETOI.

Conflict of interest: None declared.

Funding: Nil, Permission from IRB: Yes

\section{References}

1. Edwards M, Broadwater R, Tafra L, Jarowenki D et al. Progressive Adoption of Cryoablative Therapy for Breast Fibroadenoma in Community Practice. Am J Surg. 2004 September;188(3):221-24.

2. Singer AJ, Arora B, Dagum A, Valentine S, Hollander JE. Development and validation of a novel scar evaluation scale. PlastReconstr Surg. 2007 Dec;120(7):1892-7.

3. Hartmann LC, Sellers TA, Frost MH, Lingle WL, Degnim AC, Ghosh K, Vierkant RA, Maloney SD, Pankratz VS, Hillman DW, Suman VJ, Johnson J, Blake C, Tlsty T, Vachon CM, Melton LJ 3rd, Visscher DW. Benign breast disease and the risk of breast cancer. $\mathrm{N}$ Engl J Med. 2005 Jul 21;353(3):229-37.

4. Ranieri E, Barberi S, Caprio G, Civitelli L, Naticchioni E, Ceccarelli F, Rengo M. [Diagnosis and treatment of fibroadenoma of the breast: 20 years' experience]. Chir Ital. 2006 May-Jun;58(3):295-7.

5. Song R. Augmentation mammoplasty and an improved method of silastic gel breast prosthesis implantation through an areolar incision. Chinese journal of plastic surgery and burns. 1990 March;6(1):72-74. Chinese.

6. Liu X, ZhangJ,ZhouQ, Chen F et al. A Clinical Study On The Resection Of Breast Fibroadenoma Using Two Types Of Incision. Scandinavian Journal of Surgery. 2011 Jan;100(3):147-52.DOI: 10.1177/145749691110000302

7. Nisar W, ZarinM,MuslimM,Mushtaq M, Khan S. Fibroadenoma excision through periareolar incision versus an overlying incision. Pak J Surg.2013;29(3): 165-68.

\section{How to cite this article?}

Chandan A, Ali I, Manerikar K, Singh G. A comparative study of surgical accesses to breast fibroadenoma. Surgical Update: Int J surg Orthopedics.2017;3(4):162-168.doi:10. 17511/ijoso.2017.i04.12. 